\title{
THE FLUVIAL ACTION OF THE KARLA BASIN STREAMS IN A NATURAL AND MAN - MADE ENVIRONMENT
}

\author{
Moumou Ch. ${ }^{1}$, Vouvalidis K. ${ }^{1}$, Pechlivanidou S. ${ }^{1}$ and Nikolaou P. ${ }^{2}$ \\ ${ }^{1}$ Department of Physical \& Environmental Geography, School of Geology, Aristotle University of Thessaloniki, \\ 54124,Thessaloniki,Greece,cr_moumou@yahoo.gr,vouval@geo.auth.gr,sophiap@geo.auth.gr \\ ${ }^{2}$ Department of Forestry and Natural Environment, Aristotle University of Thessaloniki, 54124, \\ Thessaloniki, Greece,parisnik@yahoo.gr
}

\begin{abstract}
This study investigates the fluvial action of streams draining the Lake Karla basin, located in the plain of Thessaly, in Central Greece. Until a few decades ago, a large part of this area had been occupied by a lake. In order to find out the relation between the channel bed morphology and the oscillations of the local base level due to variations in water level and human intervention in the lake, the following streams were investigated: the flumes of Mpegiatiko, Bagiorema, Bathurema, Xerias and Maurorema. The width and the length of all channels were measured with a laser range finder while the incision and the erosive events were recorded by GPS with sub-meter accuracy. Furthermore, an integrated GIS analysis was undertaken in order to illustrate the changes in the water level of Lake Karla coupled with historical data and data from previous studies. It will be shown that there were two main evolutionary stages which controlled the local base level changes of the studied area. The first one is connected to the continuous changes in the lake's water level and its reduction from $64 \mathrm{~m}$ to $45 \mathrm{~m}$ a.s.l. This resulted in the incision of the channels and the creation of characteristic knick points upstream. The second stage is associated with the draining of Lake Karla in 1962. This intervention mostly altered the streams that developed into fine-grained material channel beds.
\end{abstract}

Key words: drained lake, Karla, Thessaly, plain, lake-level changes

\section{Introduction}

The aim of this paper is to study the natural fluvial processes in terms of the channel bed morphology developing in the hydrological basin of what once was Lake Karla and how they have been affected by human intervention in the lake. In order to be able to study the natural processes in the channels, it was necessary to explore and represent the changes that occurred on the water's surface and the volume of Lake Karla prior to its drainage, which determine the local base level of the basin.

The studied area is located in the Thessalian Plain, Central Greece (Fig.1). Lake Karla was drained in 1962, after a massive draining program for agricultural development which was also effected in other parts of Greece (e.g. Lake Kopaida). The area of the hydrological basin of the former Lake Karla is $1,121 \mathrm{~km}^{2}$ and covered the largest part of the Thessalian Plain. The basin is surrounded by Mt. Maurovouni and Mt. Kissavos to the East, by Mt. Pilio and Mt. Megavounio to the SE and south respectively and by low mountains and hills to the West.

From a geomorphological point of view, the Karla basin can be considered semi polje due to the pres- 


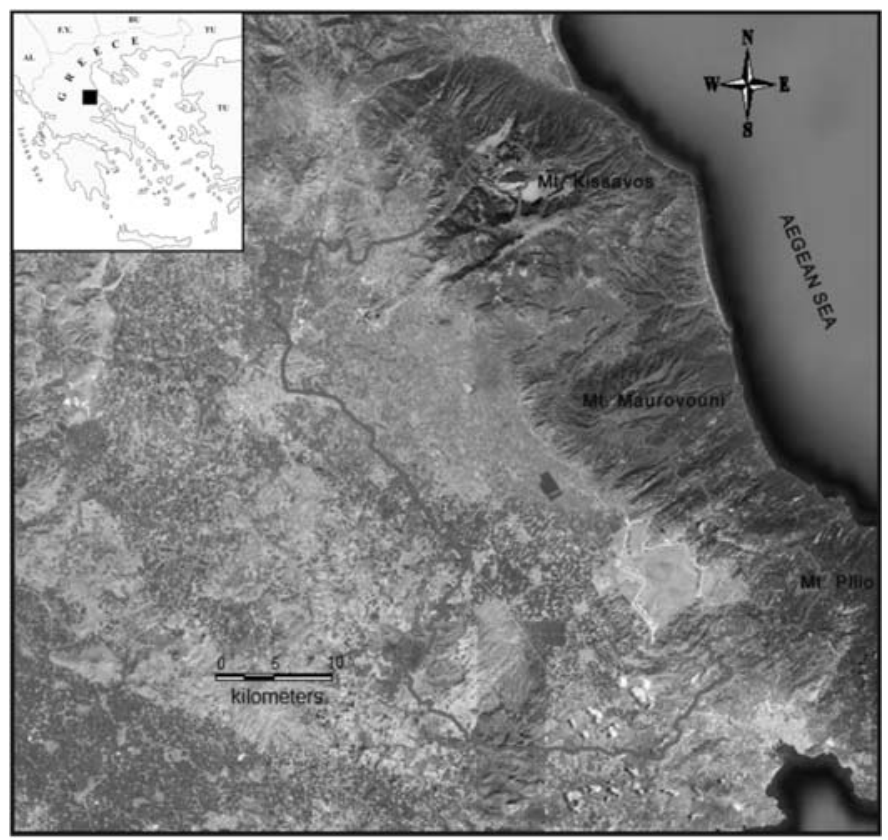

Fig. 1: Regional setting of the study area.

ence of karstified rocks and sinkholes which contributed to the underground draining of the former lake. Also, typical is the bedrock appearance at places inside the basin (hums). (Palikaridou, 1998).

\section{Materials and Methods}

A geomorphological analysis of the hydrological basin of the former Lake Karla was done through the use of the geological and topographic maps of the area. The HMGS and IGME map sheets of Agia, Farsala, Larissa, Volos, Velestino, and Platykampos at a scale of 1:50,000 were used.

A terrain analysis through the use of a digital elevation model (DEM) was performed in order to study the morphology of the lower part of the basin and to depict the impact of the local base level changes on the erosive upstream processes in the drainage network of the lake's hydrological basin. Furthermore, historical data and data from previous studies were used to determine the water level variations of the drained Lake Karla.

Finally, detailed field work was done to study the morphological changes in network channels. Concerning the morphological characteristics of the channels, the width and depth of each were measured with a laser range finder. In addition, the incision and the erosive events were recorded. For that purpose, a GPS with sub-meter accuracy was used to survey the position of all cross sections.

\section{Results}

\subsection{Historical data revealing the water level variations of the drained lake Karla}

Due to the relatively small depth of the Karla basin, the lake never exceeded $5 \mathrm{~m}$ in depth although the water surface increased significantly with a rise in water discharge. 
Table 1. Summary table of the most important bibliographical data on the water level variations of Lake Karla.

\begin{tabular}{|l|l|l|}
\hline TIME PERIOD & WATER LEVEL & WATER SUFACE \\
\hline Neolithic Age & $>50 \mathrm{~m}$ & \\
\hline Mycenaean Age & $64 \mathrm{~m}$ & \\
\hline 1921 & $50.10 \mathrm{~m}$ & \\
\hline 1945 & & $78.35 \mathrm{~km}^{2}$ \\
\hline 1953 & $45.85 \mathrm{~m}$ & \\
\hline
\end{tabular}

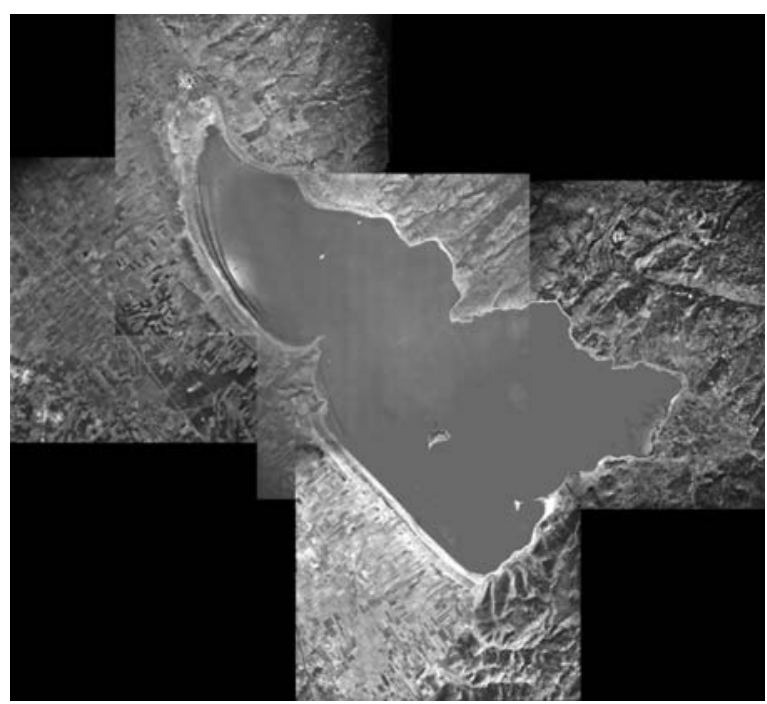

Fig. 2: Aerial photos of the year 1945, illustrating former Lake Karla (Moumou, 2007).

In this study, archaeological data, studies from other researchers, historical maps and aerial photos before the lake's drainage were collected in order to reveal the water level variations of the former lake.

During the Middle Neolithic age, the level of the lake was over 50m (Apostolopoulou - Kakavogianni, 1979), reaching a maximum water level of 64m a.s.1. during the Mycenaean Age (Grundmann, 1937; Gallis, 1989; Palikaridou, 1998). Also, it is known that the water levels in 1921 and 1953 reached 50.10m and 45.85m, respectively (Ananiadis 1956; Palikaridou, 1998). Finally, through the use of aerial photos taken in 1945 the water surface of the former Lake Karla was calculated at $78.35 \mathrm{~km}^{2}$ (Fig. 2).

A summary table (Table.1) lists levels and surface area obtained from the historical data.

\subsection{Terrain analysis}

A terrain analysis was performed in order to study the morphology of the lower part of the basin. The vertical accuracy of the HMGS topographic maps was not suitable for the study of these low relief areas. Thus, a DEM derived from the SRTM data (Shuttle Radar Topography Mission) was used. (Fig. 3) 


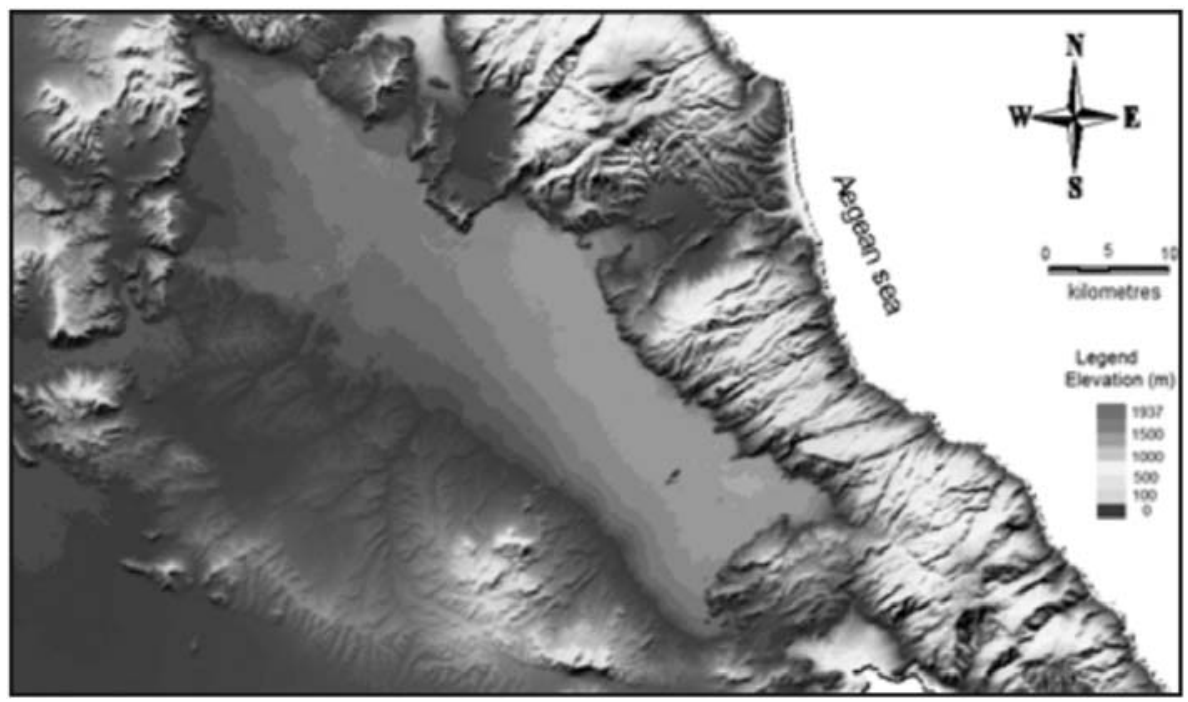

Fig. 3: Digital elevation model (DEM) of the studied area.

Based on the fact that there are no areas with distinct morphological features of deltaic deposits and alluvial fans at the lower part of the wider area including the hydrological basin of the drained lake, it was assumed that there were uniform and relatively low sedimentation rates. Thus, for the shoreline representation derived from the terrain analysis of DEM data, for the last 3000 years, the thickness of that recent layer was not extracted.

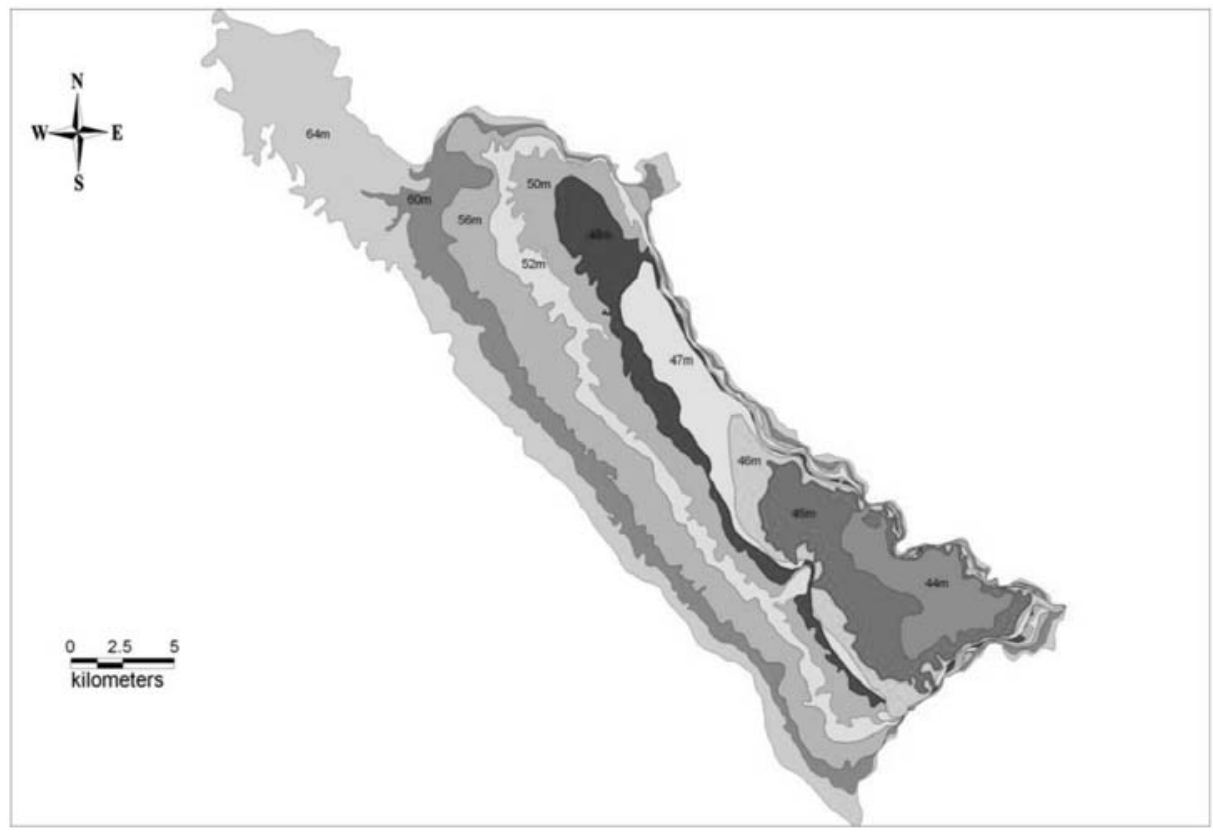

Fig. 4: Stages of shoreline migration derived from the terrain analysis of DEM data. 


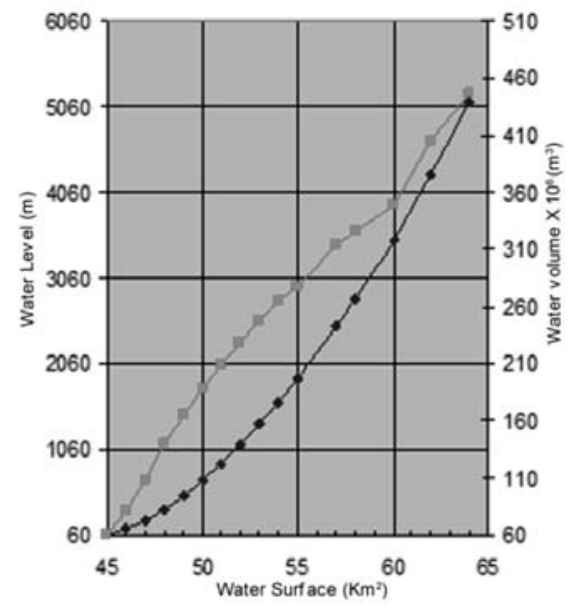

Fig. 5: Plot diagram of water level - water surface and water volume - water surface.
Table 2. Water Volume and Water Surface obtained through the use of DEM.

\begin{tabular}{|c|c|c|}
\hline $\begin{array}{c}\text { Water Level } \\
\text { (m) }\end{array}$ & $\begin{array}{c}\text { Water Volume } \\
\quad \mathbf{x}^{10} \mathbf{m}^{3}\end{array}$ & $\begin{array}{c}\text { Water Surface } \\
\text { km }^{2}\end{array}$ \\
\hline 45 & 61 & 60.67 \\
\hline 46 & 132 & 81.39 \\
\hline 47 & 231 & 108.3 \\
\hline 48 & 359 & 140.8 \\
\hline 49 & 515 & 164.5 \\
\hline 50 & 694 & 188.6 \\
\hline 51 & 895 & 209.2 \\
\hline 52 & 1115 & 228.3 \\
\hline 53 & 1355 & 248.1 \\
\hline 54 & 1613 & 264.5 \\
\hline 55 & 1889 & 278.5 \\
\hline 57 & 2490 & 313.9 \\
\hline 58 & 2813 & 326.3 \\
\hline 60 & 3496 & 348.1 \\
\hline 62 & 4269 & 405.7 \\
\hline 64 & 5125 & 446.6 \\
\hline
\end{tabular}

In order to correlate the upstream erosion rates and the channel's morphological changes with the lowered base level of the drained lake, it was necessary to know the location of the lake's shorelines and their fluctuations. Therefore, with the use of the elevation model for the absolute elevations of $44 \mathrm{~m}, 45 \mathrm{~m}, 46 \mathrm{~m}, 47 \mathrm{~m}, 48 \mathrm{~m}, 50 \mathrm{~m}, 52 \mathrm{~m}, 56 \mathrm{~m}, 60 \mathrm{~m}$, and $64 \mathrm{~m}$, a restoration of the water surface and the water volume of Lake Karla was attempted (Fig. 4, 5, Table 2).

The study of the shoreline's location obtained from the elevation model showed a large migration to the basin's center due to the constant drop in the lake's water level. On the western side of the basin, with regard to the total lowering of the lake's water level, a displacement of $4.5 \mathrm{~km}$ was estimated. On the opposite side of the basin (SE) the displacement was estimated at $1.6 \mathrm{~km}$, while in the eastern part the average displacement was only $500 \mathrm{~m}$. These displacements have greatly affected the fluvial - erosional action of streams located in that area.

\subsection{Channel morphological analysis}

Detailed field work was done to study the morphological changes in the drainage network channels. The selection of the channels was based on specific criteria. In particular:

- The channels reaching directly the $45 \mathrm{~m}$ shoreline of the drained Lake Karla were selected, since they were directly affected by the changes in the local base level.

- The channels with no human interference in their channel bottom morphology and their discharge were opted for.

- Channels were excluded due to their small development and, consequently, their small hydrological basin; thus, any changes that occurred were not measurable. 


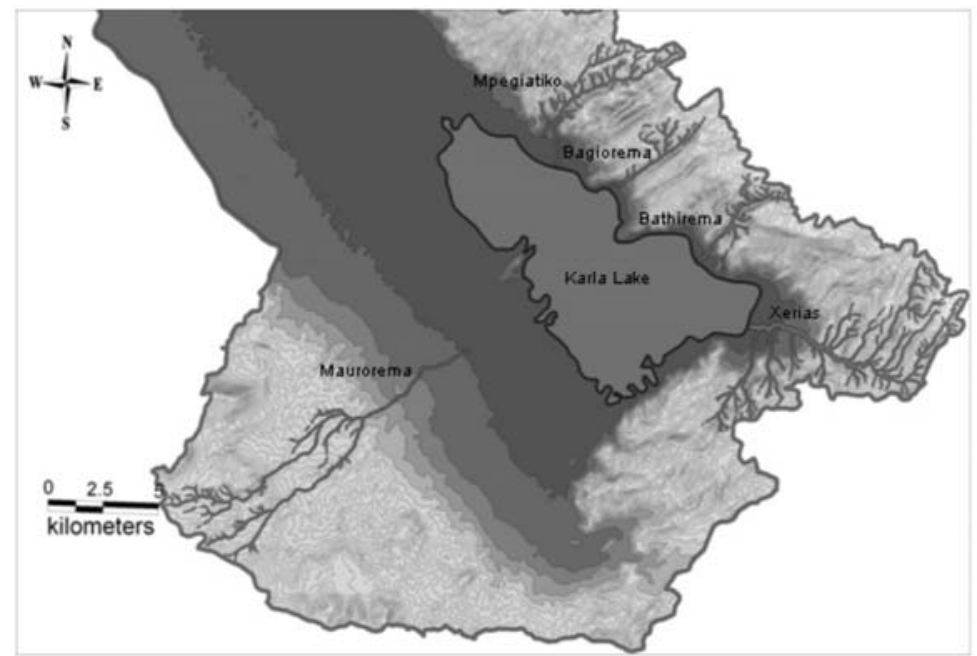

Fig. 6: Regional setting of the five main channels that were selected for the field study.

Following the aforementioned criteria, the study focused on five main channels of the following flumes: Mpegiatiko, Bagiorema, Bathirema, Xerias and Maurorema (Fig. 6)

The field survey focused on the channel sections situated on their alluvial fan deposits. The rates of upstream erosion were very low due to the last man-made change in the lake's water level $(2 \mathrm{~m})$. The only segments with high erodibility and distinctive morphological changes due to upstream erosion were those between the lake shoreline and the alluvial fan apex.

A significant factor in the final formation of the channel graded profiles was the flood event of $9^{\text {th }}$ October 2006. On that day, the estimated rainfall for the hydrological basin of the studied area was $230 \mathrm{~mm}$ (precipitation rate). These extreme discharge values triggered the erosive upstream processes and created new graded profiles.

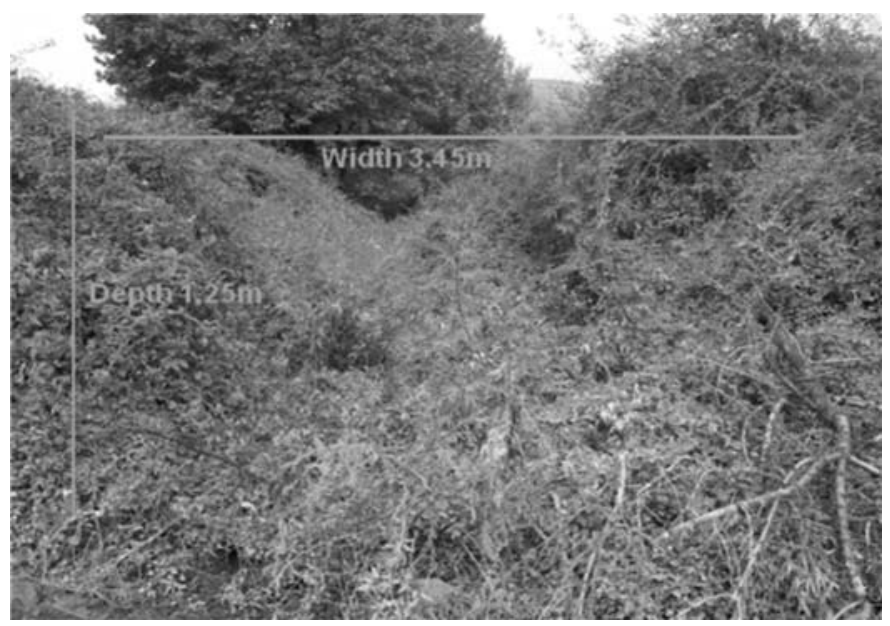

Fig. 7: Photo of Mpegiatiko stream showing the dense vegetation inside the channel bed. 


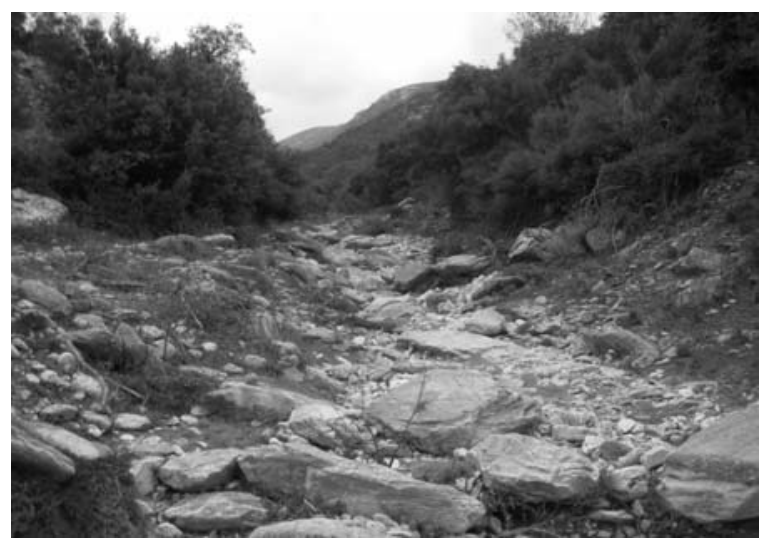

Fig. 8: Bed river of Bagiorema stream with the prevailing coarse-grained materials.

\section{- Mpegiatiko Creek}

The field study performed on the stream of Mpegiatiko showed that it is a seasonal flow stream, whose interior presents a wide channel bed with dense vegetation. No erosion was measured in the channel, apart from some incidents in the past. (Fig. 7) As the results from the morphological profile of the studied channel segment showed, the average slope is $2.8 \%$.

\section{- Bagiorema Creek}

The field study for this stream showed that it is a seasonal flow stream, presenting a small hydrological basin. The coarse-grained materials of the river bed have been a restraining factor in the erosive processes (Fig. 8). The morphological profile showed that the average slope of the Bagiorema studied channel segment amounts to $6.6 \%$.

\section{- Bathirema Creek}

The field study for the stream of Bathirema showed that it is a seasonal flow stream. The various incidents of erosion measured are older stream terraces unrelated to the recent changes in the area after the drainage of the lake. A restraining factor in the erosive processes, despite the large slope of the streambed, has been the coarse grain size of the alluvial deposits on the channel bed, and the short period of time that has elapsed since the base level change (Fig. 9). The morphological profile

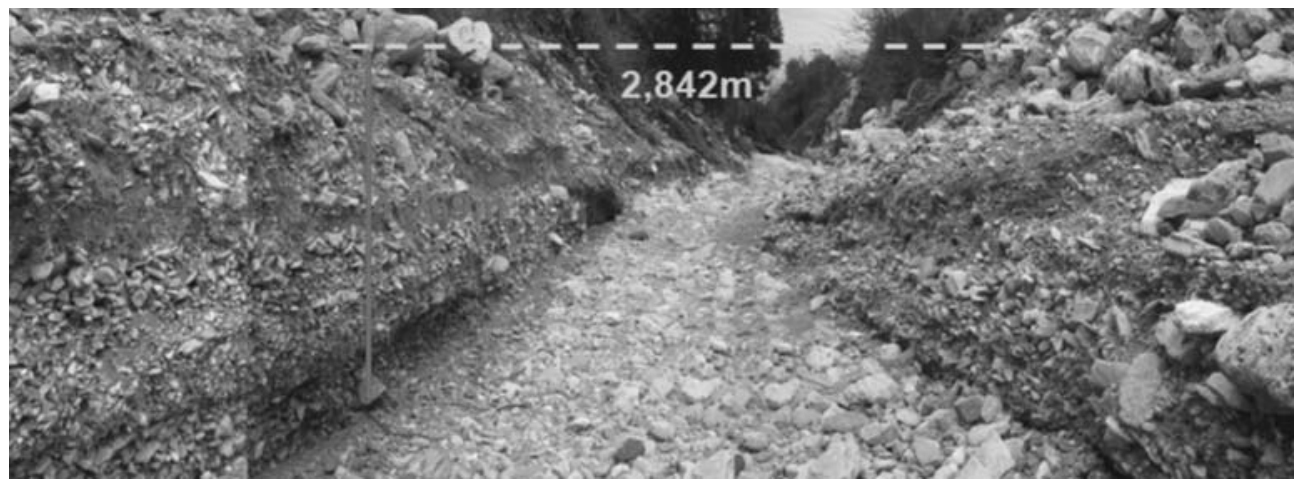

Fig. 9: Photo of Bathurema stream showing the coarse grain size of the alluvial deposits. 


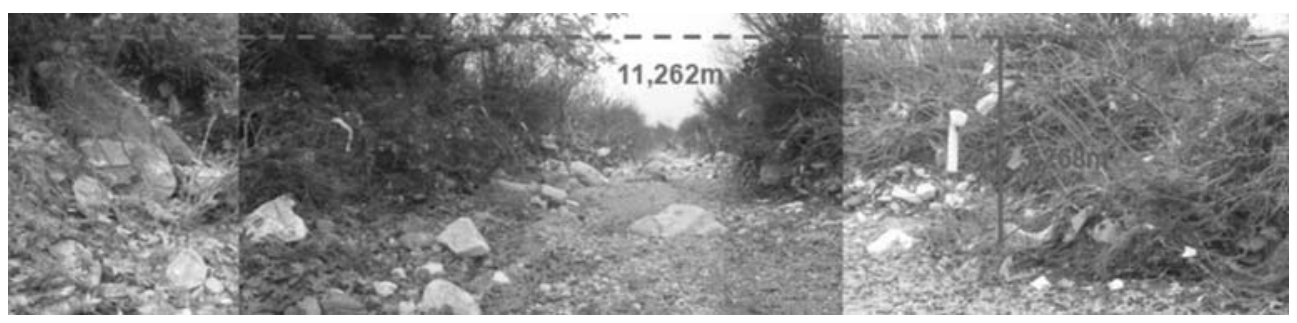

Fig. 10: Photo of Xerias stream. No erosion has been observed.

showed that the average slope of Bathirema's studied channel segment corresponds to $6.06 \%$.

\section{- Xerias Creek}

The field study undertaken for the stream Xerias showed that it is a stream with a large hydrological basin and high peaks in flow discharges. The stream flow in combination with the gentle channel slopes allowed a shortage of the streambed's alluvial sediments (coarse-grained materials close to the apex and sandy sediments further downstream). The final change of the base level after the drainage of the lake shifted the coarse bedload further downwards (Fig. 10). Finally, the processing of the morphological profile gave us an average slope channel segment of $1.8 \%$ for Xerias.

\section{- Maurorema Creek}

In the field study of the stream of Maurorema the characteristic V-type erosion was measured inside the channel, which is recent and related to the drained Lake Karla (Fig. 11). The last flood event in combination with the gentle slope of the channel segment and the fine-grained bottom are responsible for the upstream erosion and the formation of a new graded channel profile. The average slope of the studied channel segment is $1.15 \%$.

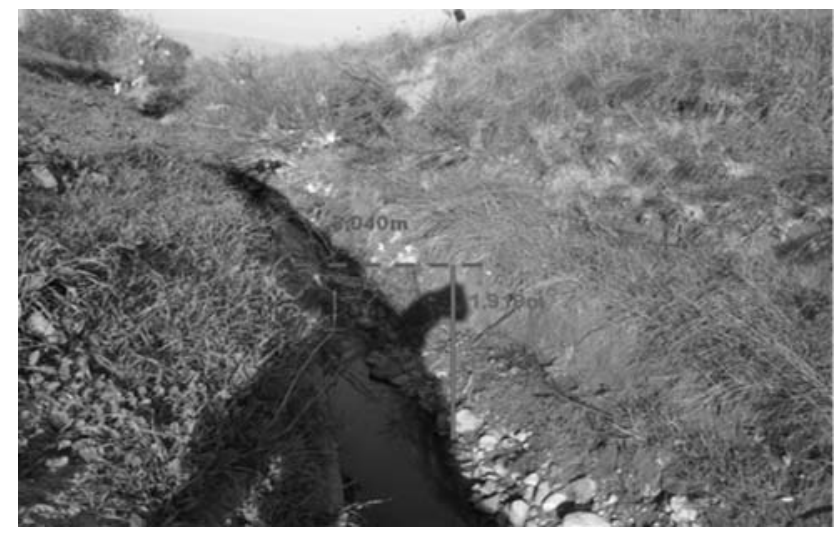

Fig. 11: Photo of Maurorema stream showing the $\mathrm{V}$ - type erosion inside the channel.

\section{Conclusions}

For each different lake level, the water volume and the surface of the lake were calculated. According to the historical and archaeological data of the Neolithic period, Lake Karla had the largest surface, delimited by a present-day contour of $64 \mathrm{~m}$. Since then, the former lake began to shrink, its 
water level reaching the absolute elevation of $45.85 \mathrm{~m}$ by 1962 , when it was eventually drained.

Probing into the coastlines of the former Lake Karla at each water level, a great shoreline displacement was observed, mainly in the western part of the basin due to the morphology of the lake's basin relief. The measured displacement reaches a maximum of $4.5 \mathrm{~km}$ and is connected to the gentle slopes prevailing in this part of the basin. In contrast, in the eastern part, lake level changes did not cause vast shoreline displacements (displacement of up to $500 \mathrm{~m}$ ) due to the steep slopes of the relief.

From the morphological analysis of the stream channels flowing into the former lake, it is clear that those that developed in the eastern part of the basin did not present erosive incidents connected to the lake's drainage. The observed terraces are connected to the fluctuations of the local base level due to water level changes of the lake. Additionally, the formation of alluvial fans consisting of coarse-grained material is the main feature of the streams (Mpegiatiko, Bagiorema, Bathyrema) developed in this part of the basin and are related to the small shoreline displacement of the former Lake Karla. Contrary to this, the drainage of the lake had an impact on the morphological profile of the streams that developed in the western part of the basin, where the bedrock is easily eroded and the relief is characterized by gentle slopes. V-type erosion inside the channels (Maurorema stream) is connected to the drainage of the former lake. Also, the latter's major shoreline displacements in this part of the basin washed over the deposited materials, resulting in the absence of alluvial fans.

In conclusion, there are two main stages for the local base level variations of Lake Karla's hydrological basin:

- The first one is associated with the continuous variations of the lake's water level, and its reduction from $64 \mathrm{~m}$ to $45 \mathrm{~m}$ a.s.1. The upstream channel erosion is continuous and the channels did not achieve equilibrium until our days. The incised channels of the torrents in their own alluvial fan deposits and the knick point migration further upstream support this theory.

- The second one is associated with the hydraulic works after 1962 and the man-made drainage of the lake. The change in the water level is about $2 \mathrm{~m}$ corresponding to the depth of the water in that final stage. The upstream erosion started only on fined-grained material channel beds (Maurorema) and not those that were developed on coarse-grained channel beds (Mpegiatiko, Bagiorema, Bathyrema).

\section{References}

Ananiadis, C. I. 1956. Limnology study of Lake Karla. Bull. De l’ Inst Oceanogr. 1083: 1-19.

Apostolopoulou - Kakavogianni O., 1979. The topography of Feres region, Thessaly, during prehistoric period (in Greek).

Gallis K., 1989. Atlas of prehistoric settlements of Eastern Thessaly plain. (in Greek).

Grundmann K., 1937. Magula Hadzimissiotiki. Eine steinzeitlichen Siedlung im Karla-See. Athenische Mitteilungen 62: 56-62.

Moumou Ch., 2007. The fluvial action of the Karla basin streams in a natural and human-made environment. Master Thesis, Aristotle University of Thessaloniki (in Greek).

Palikaridou, A., 1998. Past shorelines of the former Karla Lake. Master thesis, Aristotle University of Thessaloniki (in Greek). 